\title{
O Fotojornalismo do Big Picture: notícias contadas por fotografias ${ }^{1}$
}

\author{
The photojournalism of Big Picture: news told by photographs
}

\author{
Esp. Anna Letícia PEREIRA DE CARVALHO \\ Faculdade Cásper Líbero (Brasil) \\ annaleticia@gmail.com
}

Recibido: 31 de julio de 2013

Aceptado y Publicado: 16 de octubre de 2013

\section{Resumen}

Estudar a fotografia é importante porque ela está relacionada com o desenvolvimento da sociedade e porque é apropriada por diversas disciplinas, como a história, a sociologia, a antropologia, a arquitetura, dentre outras. Podemos enxergar o mundo através de diversas óticas e uma dela é perceber a fotografia como dispositivo de comunicação.

O artigo teve como objetivo geral um estudo no campo da Comunicação, mais especificamente da Cultura Visual e do Fotojornalismo, através da reflexão e análise referente ao objeto ainda pouco estudado, que são as imagens fotojornalísticas propagadas por um suporte virtual. Foi feito um recorte de imagens do site Big Picture, que tem como finalidade contar notícias através de fotografias, com a função de produzir informação imagética na Internet.

O site Big Picture é um exemplo de como os dispositivos imagéticos atuais precisam ser observados pois procuram produzir uma nova experiência sensitiva para o espectador. A exploração de mecanismos que contribuam para esse novo caminho faz com que os diálogos com outras mídias ou mesmo com a bagagem do espectador se multiplique. A fotografia se insere nesse caso. Ela é presença forte na expansão das manifestações contemporâneas, onde cada vez mais as imagens se tornam experiências de interação entre o dispositivo e o observador.

\footnotetext{
${ }^{1}$ Artículo producto de una Ponencia presentada en el VI Encuentro Panamericano de Comunicación COM PANAM 2013 celebrado la Escuela de Ciencias de la Información de la Universidad Nacional de Córdoba (Argentina), durante los días 5, 6 y 7 de junio de 2013.
} 
A partir daí, podemos citar o diferencial do site boston.com/bigpicture, cujo nome, "foto grande", explica metaforicamente a sua intenção. As imagens aqui não são apenas acompanhamentos, elas são as notícias. São, em sua maioria, imagens digitais em alta resolução mostradas já em tamanho grande e funcionam como dispositivos de informação, uma vez que possuem a intenção de chamar a atenção dos leitores para elas e não, necessariamente para os textos. São imagens provenientes de vários locais da Internet, como as fotos da agência internacional de notícias Reuters e o site Gettyimage. Todos os dias vemos uma seleção de aproximadamente 30 fotos que narram os fatos que marcaram e que construíram notícias. Guerras urbanas, eventos naturais, festas populares, figuras populares, tudo isso de modo a tentar inovar num novo suporte, mas calcado na tradição do fotojornalismo.

Nesse sentido foi desenvolvido um estudo que abrange a Cultura Visual e nova era da informação, representada pela Internet, de modo a verificar os impactos desse novo suporte no cenário da Comunicação e, principalmente, como se dá a veiculação de imagens jornalísticas nesse meio.

Através dessa pesquisa, acreditamos que foi possível refletir sobre o papel da imagem como construtora de uma nova cultura na sociedade atual que abre caminho para novos sistemas de significados que estão presentes dentro da globalização e, consequentemente, na sociedade da informação. A reflexão permite o aumento do espaço teórico no que se refere à análise de imagens e a recepção midiática dentro de um contexto histórico-cultural. O estudo de imagens é, portanto, necessário para o entendimento das representações na atualidade e para o crescimento de novas propostas teóricas que tenham em pauta esse tipo de investigação.

\section{Abstract}

Studying photography is important because it is related to the development of society and because it is suitable for various disciplines, such as history, sociology, anthropology, architecture, among others. We see the world through different optical and realize it is photography as a communication device.

The article aimed to study the field of communication, more specifically of the Photojournalism and Visual Culture, through reflection and analysis for the object still understudied, photojournalistic images that are propagated by a virtual support. Was made 
by a clipping site's Big Picture photos, which aims to tell stories through photographs, with the function of producing imagery information on the Internet.

The site Big Picture is an example of how the current pictorial devices must be observed as they seek to produce a new sensory experience for the viewer. The exploration of mechanisms that contribute to this new way makes the dialogues with other media or even with the baggage the viewer to multiply. The photograph is part of this case. She's strong presence in the expansion of the contemporary manifestations, where increasingly the images become experiences of interaction between the device and the observer.

From there, we can mention the differential site boston.com / big picture, whose name, "Big picture", metaphorically explains its intention. The images here are not only accompaniments, they are the news. They are mostly digital images in high resolution now shown full size and function as information devices, since they have the intention to draw readers' attention to them and not necessarily for the texts. These are images from various Internet sites, such as photos of the international news agency Reuters and Gettylmage site. Every day we see a selection of approximately 30 photographs that narrate the events that marked that built and news. Urban wars, natural events, festivals, popular figures, all this in order to try to innovate in new support, but grounded in the tradition of photojournalism.

Accordingly a study was developed covering Visual Culture and the new information age, represented by the Internet, in order to verify the impact of this new medium of communication in the scenario, and especially how is the placement of journalistic images in this medium.

Through this research, we believe it was possible to reflect on the role of image as a builder of a new culture in our society that paves the way for new systems of meanings that are present within globalization and hence the information society. Reflection allows increasing the theoretical space in relation to image analysis and media reception within a historical and cultural context. The imaging study is therefore necessary to understand the representations in the present and for the growth of new theoretical proposals on the agenda that have this type of research.

Palabras Clave: Fotojornalismo, Big Picture, escenarios digitales, cultura visual, nova era da informação. 
Key Words: Photojournalism, Big Picture, digital context, visual culture, new information age.

\section{Introducción}

$\mathrm{Na}$ história do jornalismo, a fotografia se apresenta como um dos elementos principais da produção jornalística. $\mathrm{Na}$ era digital, percebe-se que a fotografia vem passando por transformações que se referem à estética e à linguagem, já que a imagem de imprensa não mais pertence somente à linearidade do papel, mas também aos novos suportes digitais onde presenciamos possibilidades de interação e observação.

A fotografia utilizada nos meios digitais como suporte de informação imagética é o alvo deste artigo, pois percebemos que a produção fotojornalística na web, apesar de partir de padrões tradicionais, vem tentando construir uma nova maneira de disponibilizar conteúdo visual no ambiente ilimitado da internet. Buscamos neste trabalho entender as dinâmicas envolvidas no processo jornalístico visual online de modo a compreender como as narrativas se aplicam à fotografia que pretende ser de imprensa. Consideramos o fotojornalismo como um produto que pode gerar conhecimento, provocar sensibilização, contextualizar e incitar um olhar demorado. Não pretendemos construir uma fórmula de veiculação de imagens jornalísticas, mas desenvolver um debate acerca de como a fotografia jornalística vem arquitetando o seu espaço no mundo digital para que a sua dimensão informativa seja percebida e observada.

O site fotojornalístico Big Picture, do jornal The Boston Globe surgido em 2008, é um exemplo de como os dispositivos imagéticos procuram produzir uma nova experiência sensitiva para o espectador. A exploração de mecanismos que contribuem para esse caminho novo faz com que os diálogos com outras mídias ou mesmo com a bagagem do espectador se multipliquem. A fotografia se insere neste caso. Ela é presença forte na expansão das manifestações contemporâneas, na qual, cada vez mais as imagens se tornam experiências de interação entre o dispositivo e o observador.

\section{Antecedentes}

\subsection{Big Picture}

No contexto de inovações dos suportes das mídias surge o site Big Picture ${ }^{2}$, criado e

\footnotetext{
${ }^{2} \mathrm{Http}: / /$ www.boston.com/bigpicture
} 
administrado pelos editores de fotografia do jornal The Boston Globe ${ }^{3}$, com o objetivo de publicar fotografias para contar notícias mundiais. Criado em 2008, por Alan Taylor, o blog teve em seus primeiros 20 dias mais de 1,5 milhão de visualizações. Ele surge como uma quebra de paradigma na comunicação imagética via internet, uma vez que traz coberturas fotográficas de grande formato, sob a ótica do fotojornalista.

Dois aspectos chamam a atenção para este fotoblog 4 além de estar relacionado a um veículo de imprensa (o jornal The Boston Globe), é também o pioneiro em publicação de imagens em alta resolução. Em tempos de aumento e expansão da banda larga e com a variedade de meios de se conectar à rede, esta convergência digital é uma alternativa para o uso do fotojornalismo na internet. O Big Picture reúne e organiza fotografias de várias origens e gera novas formas de conteúdo, apresentando fotorreportagens e ensaios, remidiatizando-as para um tema em comum com o objetivo de alcançar novos eixos de audiência e visibilidade.

A maioria das imagens são provenientes de Agências de Notícias como a Associated Press, Reuters, e Getty Image, outras vêm de fontes oficiais, como a Nasa, e outras de fotógrafos que queiram dividir suas fotografias com o Big Picture. As reportagens fotográficas são geralmente postadas às segundas, quartas e sextas-feiras, sempre acompanhadas com legendas explicativas. Cada publicação, atualmente, tem cerca de 30 fotos de várias agências de notícias reunindo diversos pontos de vista sobre o fato publicado ou, em alguns casos, somente com um.

Um fotoblog como o Big Picture está inserido num contexto cultural particular, onde a forma como a mensagem é transmitida é aliada a um conjunto de profissionais que encaram a unidade jornalística como uma maneira de atender às regras impostas pela instituição e ao público ao qual o jornal se destina, criando assim, um discurso característico do veículo.

Nas tendências atuais de propagar informação, a proposta do blog Big Picture torna-se interessante por mostrar um olhar sobre um mesmo tema apresentando fotografias de diversas agências, do público ou mesmo de um único fotógrafo. No entanto, para apreender

\footnotetext{
3 Jornal estadounidense de Boston, Massachusetts e pertencente ao The New York Times Company desde 1993. Foi lançado na internet em 1995 e está no ranking dos 10 webjornais com maior prestígio na América. Está sediado no endereço www.boston.com.

${ }^{4}$ Fotoblog é um derivado do "weblog". O weblog é como um diário de anotações ou memórias online. O fotoblog tem a mesma definição, porém, é composto apenas de fotos e legendas. Uma característica importante do fotoblog é a interatividade: outras pessoas podem inserir comentários sobre a imagem que foi enviada (Fonte: http://fotoblog.uol.com.br/stc/faq_geral.html\#1).
} 
a capacidade de comunicação do fotoblog é necessário o amadurecimento do olhar de quem acessa. O Big Picture é, portanto, um objeto para novas reflexões sobre o impacto das fotografias na mídia online, que corresponde a um campo novo, em pleno desenvolvimento mas que, todavia, é um objeto expressivo e capaz de gerar fortes impactos na sociedade.

\section{Metodología y discusión}

\subsection{A Fotografia na Cultura Visual}

André Rouillé, professor na Université de Paris VIII, nos fala que a fotografia "só foi imagem de poder enquanto pôde ficar em sintonia com o sistema, os valores e os mais emblemáticos fenômenos da sociedade industrial: a máquina, as grandes cidades e esta extraordinária rede que as interliga, a estrada de ferro" (ROUILLÉ, 2009, p. 48). O autor observa atentamente o caminho histórico e teórico por qual a fotografia passou até os dias atuais e critica a indicialidade, afirmando que a teoria que coloca a fotografia como traço do real apenas seguiu uma visão de cunho ideológico e não leva em consideração a utilização da fotografia em seus diferentes contextos. Para o historiador, a fotografia é mais do que um efeito luminoso, ela é um processo.

Ele nomeia, ainda, duas grandes funções da fotografia: a fotografia-documento e a fotografia-expressão. Para Rouillé (2009), o status de documento foi originado a partir da crença de que a fotografia funciona como prova, pois contém a relação direta com o referente. A discussão acerca desse status culminou na abertura do pensamento e deu origem ao que o autor chama de "fotografia-expressão":

A fotografia-expressão exprime 0 acontecimento, mas não 0 representa. Levaremos em consideração, aqui, a hipótese segundo a qual a passagem do documento-designação para documento-expressão repercute na fotografia como um fenômeno mais global: a passagem de um mundo de substâncias, de coisas e de corpos, para um mundo de acontecimentos, de incorporais. A passagem de uma sociedade industrial para uma sociedade da informação. A sociedade da informação, que se estende ao ritmo das redes digitais de comunicação, age profundamente sobre o conjunto das atividades, particularmente sobre as práticas e as imagens fotográficas, segundo processos muitas vezes subterrâneos e silenciosos, mas que colaboram para o esgotamento da fotografia-documento. (ROUILLÉ, 2009, p. 137)

A condição de reprodutibilidade da fotografia e sua rapidez de produção atuam como 
condicionantes da mediação, de modo que os conteúdos fotográficos ficam, muitas vezes, perdidos dentre tantas imagens. A reprodução por si só já retira a imagem fotográfica de seu contexto original e, dependendo de seu uso, pode ser encarada de diferentes formas. A fotografia, assim, sendo passível de reprodução e edição, ganha o terreno do jornalismo por sua condição eficiente, substituindo em muitos casos as gravuras e ilustrações outrora utilizadas. O fotojornalismo foi, portanto, o impulso que a fotografia recebeu para se firmar como essencial à sociedade industrial.

O fotojornalismo provoca o que Rouillé (2009) chama de "crise da verdade" , pois os limites entre a fotografia como documento e a fotografia como expressão se fundem e se distorcem, fazendo com que a noção do real representado seja relacionado principalmente à designação. Desse modo, a aderência não é direta e, portanto, se considera todas as outras imagens que operam na constituição da cultura visual seguindo, em sua maioria, regimentos estéticos.

Com base nisso, o dispositivo fotográfico funciona como modelo de comunicação e transmissão que se dá não somente pelas fotografias-documentos, mas também por qualquer elemento da ordem visual, inclusive relacionados à fotografia-expressão de modo a criar contradições e desmentir a ilusão anteriormente proposta. Para Rouillé (2009), a fotografia-expressão assume um caráter indireto. O site Big Picture, ao misturar imagens que podem ser consideradas por muitos de ordem direta (notícias instantâneas com a estética do testemunho) com imagens da ordem indireta (ensaios, fotorreportagens, etc) desmistifica os clichês e propõe um novo método de reconhecimento da representação e parte para "jogos infinitos das interferências e das distâncias" (ROUILLÉ, 2009, p. 159).

Sempre prestigiamos a fotografia como um complemento da notícia escrita ou reportagem e a atenção dada ao webfotojornalismo só se baseava em pequenas imagens no layout dos sites, algumas com a possibilidade de serem um hiperlink para a mesma imagem em tamanho maior. A imagem não deixa de ter o seu passado impresso, ela ainda precisa de uma contextualização, uma regra do fotojornalismo que não leva em consideração o suporte, como afirma Buitoni (2009):

\footnotetext{
${ }^{5}$ A crise da verdade manifesta-se no interior da fotografia documental, destruindo seus valores fundamentais e distorcendo seus limites. A imagem não remete mais de maneira direta e unívoca à coisa, mas a uma outra imagem; ela se inscreve em uma série, sem origem definida, na cadeia interminável das cópias. O mundo dissolve-se dentro dessas séries infinitas. Instala-se a dúvida, e confundem-se os limites entre o verdadeiro e o falso (...). Ao contrário do que pode ser dito, a fotografia documental não teve como sua função principal representar o real, nem de torná-lo verdadeiro ou falso, mas, de designá-lo, de ordenar o visual. (HORN, 2012, p. 6).
} 
Ao analisarmos jornais na web, temos a impressão de que o panorama póstecnologia digital ainda não foi suficientemente assumido pelos formatos jornalísticos presentes na rede. Os modos de ver e de ler estão ainda muito próximos do que acontece no jornalismo impresso convencional. (BUITONI, 2009, p. 223)

O site Big Picture apresenta um diferencial. As imagens sequenciadas provocam uma narrativa que acontece pela visão da publicação como um todo ou na junção de apenas algumas imagens. Elas apresentam vividamente notícias, fotorreportagens e ensaios, uma vez que as fotografias já aparecem na interface do site em tamanho grande também. Não temos como ignorar a plasticidade das fotografias, que representa um dos modelos de utilização de fotografias digitais na internet e um caminho para as possibilidades do uso de fotografia nesse novo suporte, pois o aprofundamento das notícias é dado pelas imagens.

A capacidade de mutação das imagens contemporâneas nos faz pensar numa complexidade imagética, uma vez que o fluxo de produção envolve imagens e suas mutações em diversas ordens: fotografias, montagens, narrativas, interações, etc; processos que tornam a reflexão de Català $(2005)^{6}$, fundamentais para o entendimento da representação na cultura atual. Para ele, o cenário de produção de imagens equivale a uma cultura visual, visto que as imagens se manifestam na forma de uma ecologia do visível.

O pesquisador procura distanciar o conceito de imagem do conceito de texto, dado que o fluxo temporal expressado pelas imagens compreende algo além da informação puramente verbal. Para Català (2005), a imagem é também produto da imaginação e os fenômenos da cultura visual vêm para unir o conceito de imagens ao conceito de texto, de modo a redefinílo:

O texto, evidentemente, qualifica e raciocina de forma mais poderosa e incisiva que quaisquer imagens, mas estas, em contrapartida, permitem uma imediata visualização das complexidades que os textos contém, e o faz de uma maneira que a disposição dura e linear da língua escrita se vê impossibilitada de administrar (exceto nos novos hipertextos, que, ao fim e depois, são em muitos sentidos um expoente a mais do exercício de conversação do texto em imagem que promove o computador). (CATALÀ, 2005, p. 69) ${ }^{7}$

\footnotetext{
${ }^{6}$ Joséph M. D. Català é pesquisador da Universidade Autônoma de Barcelona.

${ }^{7}$ Trecho livremente traduzido pela autora do artigo.
} 
O estudioso, desta maneira, concebe a noção de imagem complexa como aquela que privilegia operações estéticas características da subjetividade e da emoção, de modo a atentar para formas que não estejam relacionadas à mimese. Na epistemologia da imagem complexa, ele determina que a imagem tradicional esteja relacionada à ciência e à objetividade. Nestas, a imagem não provoca reflexão no observador passivo. A imagem tradicional é transparente, mimética, ilustrativa e espectatorial o que mostra como durante a história da imagem, esta sempre esteve relacionada à objetividade e ao realismo. Essa visualidade científica na cultura visual, todavia, pode ser desmentida pela imagem complexa (CATALÀ, 2005).

A imagem complexa se relaciona com a arte e com a subjetividade, uma vez que ela é opaca e exige um olhar demorado. Além disso, Català (2005) a entende como positiva, reflexiva e interativa, pois a imagem complexa deve ser exposta e permitir ampliar a visão do observador ativo. A complexidade aparece na reflexão e forma, o que o pesquisador chama de visualidade pós-científica.

Diante dessas constatações, pode-se dizer que o pesquisador desenvolve um conceito epistemológico que tem como fundamento trazer interrogações acerca da imagem e como ela pode se tornar complexa. Partindo disso, há que se levar em consideração também a ação do observador e como ele investe o olhar sobre as imagens complexas. Este olhar ativo é chamado de "mirada", resultado da articulação entre o olhar investido sobre a imagem e a imagem, ou seja, uma "mirada" complexa.

A ativação da "mirada" complexa resulta no entendimento das imagens e a relação delas com as dimensões subjetivas e objetivas, no espaço e no tempo e no pensamento que provêm dessas articulações de modo a entender as consequências epistemológicas provenientes da imagem complexa. A "mirada" se desenvolve no pensamento imagético, ou seja, na capacidade de não só pensar sobre as imagens, mas também pensar com elas.

A complexidade visual pode ser encontrada em diversos produtos imagéticos e audiovisuais, especialmente quando o produto passa por alguma articulação que interfira no espaço e no tempo, e quando permite ao observador interagir com ele. A mistura de produtos de origens diferentes (fotografias, vídeos, multimídia, etc) também pode ser um caminho para a complexidade visual, visto que os produtos ultrapassam os artifícios estéticos individuais, o que, por sua vez, estimula a produção de sentido.

O conceito de "imagem complexa" desenvolvido por Català (2005), nos ajuda a refletir sobre 
essa capacidade do fotojornalismo e o seu processo representativo. Isso porque o estudioso propõe uma noção diferenciada de leitura do mundo por meio de imagens. Ele usa a noção de complexidade de Edgar Morin ${ }^{8}$ para mostrar que é possível investir o olhar sobre as imagens, de modo a perceber que elas possuem profundidade e são carregadas não só de objetividade, mas também de subjetividade.

A simultaneidade com que vemos as imagens no mundo nos mostra que é necessário um processo de imersão para, somente assim, conseguirmos entendê-las complexamente. Dessa forma, é possível pensar como as imagens estão presentes na construção de conhecimento.

As imagens complexas têm presença importante na comunicação digital e virtual porque nesses mecanismos pode-se explorar as diversas possibilidades de conexões entre as imagens, de modo que o grau de complexidade nos ajuda a perceber as imagens em vários níveis.

Català (2011) abre o caminho pelo qual é preciso levar em consideração o conjunto de imagens, como elas se relacionam e transmitem intenções para outras imagens. Nessa "ecologia da imagem", como ele diz, tudo está se inter-relacionando e os modos de percepção estão sendo alterados por causa dessa constelação imagética. A era da visão trouxe a diferença entre ver e olhar. $\mathrm{O}$ olhar se torna atento e descobridor dessas várias camadas e as imagens são fluidas, modernas e possuem, sem dúvida, diversas superfícies.

É importante notar que, considerar a ecologia da imagem é pensar principalmente na fotografia-expressão, pois enquanto a fotografia-documento possui o seu lugar no mundo das coisas, a fotografia-expressão atua sobre o conjunto de elementos que envolve os fatos jornalísticos, as redes digitais, as informações em tempo reais, a originalidade e criatividade daqueles que a produzem. A fotografia-expressão representa dialeticamente a razão e a emoção e se dá também pela possibilidade de articulação de diversas imagens, ou seja, pode se dar através de uma ecologia do visível. Isso não implica que a fotografia-documento não possa constituir também uma ecologia.

O conceito de fotografia-expressão cunhado por Rouillè (2009) está diretamente relacionado ao conceito de imagem complexa de Català (2005) pois, para ambos, a fotografia pode carregar elementos antes dispensados pela fotografia-documento, tais como a dimensão

\footnotetext{
${ }^{8}$ Pesquisador emérito do CNRS (Centre National de la Recherche Scientifique). Formado em Direito, História e Geografia, realizou estudos em Filosofia, Sociologia e Epistemologia. É considerado um dos principais pensadores sobre a complexidade. Fonte: http://www.edgarmorin.org.br/vida.php
} 
poética, a subjetividade do autor e a existência do Outro em relação ao dispositivo fotográfico. A fotografia-expressão e a imagem complexa contribuem para o processo de representação e as reflexões originadas a partir desses conceitos buscam o sentido da imagem e não a coisa a qual ela se refere.

Ambos os estudiosos refletem sobre as estratégias visuais que são encontradas nas imagens atuais, estratégias as quais envolvem também as dimensões espacial e temporal e estão relacionadas aos processos mentais de reconhecimento e memória. Se aplicarmos esses conceitos ao fotojornalismo, aqui estudado, poderemos perceber que a utilização da imagem como forma de expressão e conotação contribui para a humanização do jornalismo, o que por sua vez, apreende a complexidade do fato divulgado.

É importante ressaltar que o consumo de imagens jornalísticas é cotidiano e essencial e que a vida na sociedade capitalista gira em torno da compra de produtos, tanto do ponto de vista do consumo quando da ideologia, mas a diferenciação da imagem ilustrativa para a imagem complexa, aquela que possui camadas de leituras, torna o consumo diferenciado, já que o alvo pode ser tanto o espectador comum tanto aquele que está preparado para ler as imagens culturalmente.

\section{Conclusiones}

\section{O fluxo editorial e a "fotografia-expressiva-jornalística"}

Para além do uso da tecnologia, fotografar na era da internet sob a égide do fotojornalismo é comunicar, o que por sua vez é trocar informações, emoções, ou mesmo dividir conhecimento. O trabalho do fotógrafo já entra cada vez mais num sistema em que a concepção da imagem resulta do trabalho de diversos profissionais.

O fotojornalismo estabelece uma maneira própria de comunicação entre o observador e o mundo. Ele apresenta a versão dos fatos, apesar de não ser considerado a verdadeira testemunha de um acontecimento. Sua ação comunicativa só é efetiva quando estabelece uma relação com o imaginário social, pois, a partir do fotojornalismo podemos construir visualidades que potencializam o imaginário e isso se dá através do discurso visual.

As fotografias ocupam posições de destaque em alguns jornais e até mesmo já se destacam em primeira página, isso porque elas podem possuir mais força do que os textos dentro da dimensão jornalística. Elas têm o poder de sensibilização, ou seja, atingem os indivíduos no nível da estética e da emoção. Também possuem a dimensão informativa e, na 
contemporaneidade, estamos acostumados a ver o mundo através de imagens. Em muitos casos, as fotos tomam o lugar do verbal, porém, percebe-se que apesar do entendimento das simbologias presentes nas fotografias, poucos a reconhecem como um modelo de pensamento, costumam enxergá-las apenas como factuais, como índices. Antes de ser publicada a fotografia jornalística passa pelo processo de edição. É publicada aquela que ganhou o privilégio de ser escolhida dentre tantas outras do mesmo fato. Essa seleção passa pelo caminho que leva em consideração a linha editorial do jornal ou webjornal e geralmente ocupa a função de representar uma notícia imageticamente. Além disso, em muitos casos, a fotografia é escolhida pela sua relevância factual, ou seja, algumas fotografias são publicadas por serem caracteristicamente "testemunhas" de um fato. No entanto, a arbitrariedade da edição ainda domina a publicação e toda a decisão é parcial, porque envolve um suporte ideológico em que a qualidade e o comportamento são ditados anteriormente. A edição legitima o poder existente nos meios de comunicação, que por sua vez, também leva em consideração aquilo que mais agrada ao público, o que será visto e discutido.

A fotografia publicada é resultado de um pensamento complexo do editor. Os ensaios e fotorreportagens como do site Big Picture resgatam fotografias de diversos canais e, por meio do sequenciamento e junção delas, formam painéis, narrativas e olhares sobre acontecimentos que são preparados pelo editor para atrair o público consumidor desse tipo de pensamento imagético. As fotografias publicadas representam estados de reconhecimento, dos quais as imagens servem como catalisadoras de um evento, tornandoos reais, tornando-os passíveis de serem acreditados.

De forma geral, a edição é o processo pelo qual uma obra recebe corte, substituição, deslocamento, inserção, reorganização e padronização no estilo da editoria. A edição é, portanto, um dos procedimentos que singularizam o jornalismo, o tratamento final das informações obtidas e o mecanismo que o jornal utiliza para selecionar e organizar conteúdos com o intuito de formar uma narrativa, de modo hierarquizado e seguindo a linha editorial. No caso do Big Picture, a edição também expressa a visão estética no conteúdo imagético.

Fotos impressionantes resultam em pautas sólidas. Editores de fotografia em revistas, jornais, agências ou sites leem atentamente listas de notícias para determinar quais são apropriadas para informações pictóricas, quais precisam de uma ilustração ou elemento gráfico e quais não precisam de nenhum trabalho artístico. Com o pessoal e recursos limitados - a maioria dos jornais, revistas e 
sites se encaixam nessa categoria - editores devem optar por cobrir artigos ou matérias de primeira página com certa dose de interesse visual imagético. (KOBRÉ, 2011, p. 126)

A estrutura da fotografia jornalística não é isolada, ela é sempre acompanhada de um texto (título, notícia e legenda), de outras fotografias e da interface do suporte onde se encontra. $\mathrm{O}$ modo como o fotojornalismo é exposto representa muito sobre a edição do jornal, sobre a estética para sensibilização do usuário e os modelos de pensamento envolvidos nessas constituições. As legendas que participam dessa esfera de comunicação ampliam a informação, já que a contextualização é determinante para a compreensão da fotografia jornalística. Pode-se pensar que a legendagem é algo fácil de se fazer, no entanto, reduzir a fotografia em poucas palavras é um processo difícil, visto que a legenda deve complementar e aprofundar a leitura da imagem.

Algumas mudanças têm mostrado procedimentos diferentes de se utilizar a fotografia no meio digital e isso envolve desde a sua origem, até o modo como ela é empregada no espaço visual do suporte online. O Big Picture se diferencia também de outros modelos de utilização de imagens da imprensa no que se refere à qualidade das imagens. Nele, explorase a riqueza de detalhes, as cores, as texturas, as sombras e o degradé, fazendo com que as fotografias tenham participação fundamental dentro da cultura jornalística.

Em fotoblogs como o Big Picture, a maioria das imagens provém de agências de notícias. Observa-se, então, a terceirização dos serviços fotográficos, a qual mostra que a formação do discurso está mais intimamente relacionado ao editor, uma vez que seu papel é unir as fotografias das agências com as notícias relacionadas ao acontecimento original. Logo, podemos perceber que os ensaios e fotorreportagens presentes no nosso objeto de estudo ocorrem devido à prática da reprodução de notícias e à tentativa de expansão da mesma por meio de imagens.

A equipe de edição tem papel fundamental na formação da narração, pois ela busca nos bancos de dados e nas agências de notícias as fotografias que serão utilizadas, faz o tratamento das imagens quando necessário, as seleciona e as sequencia, de modo a mantêlas coerentes com a notícia e com a linha editorial do meio. $O$ resultado disso é o processo criativo jornalístico com a união de texto, imagem e interface, já que as escolhas feitas pelos editores constituem redes de pensamentos complexos que determinam o percurso editorial e as relações comunicativas provenientes do processo de criação. 
A edição fotográfica obedece a diversos parâmetros originados da linha editorial, que incluem os critérios de noticiabilidade; os critérios estéticos, presentes na plasticidade dos elementos visuais, e como isso interfere na narrativa e no discurso visual; as opções políticas e sociais das empresas de comunicação; a relevância das narrativas noticiosas frente ao público-alvo do meio de comunicação; os valores culturais e morais da representação fotográfica, uma vez que a fotografia produz a visibilidade do outro; a escolha por uma imagem que transmite emoção ou o máximo de informação, já que a seleção da imagem relaciona-se com a característica da notícia e dos critérios de noticiabilidade, por outro lado, pode-se escolher uma imagem que emocione ou outra que assuma a noção de testemunho e de fidelização do assunto proposto.

No fundo, a representação de um instante de um acontecimento está praticamente sujeita à utopia: com exceção de algumas imagens em que se cultiva o aleatório (instantâneos fotográficos automáticos, em intervalos regulares, por exemplo), esse instante é sempre escolhido em virtude do sentido a exprimir, depende da fabricação. A doutrina do instante pregnante, por sua insistência sobre a significação de conjunto da imagem, detaca esse caráter fabricado, reconstituído, sintético, do dito 'instante' representado - que só é obtido de fato por justaposição mais ou menos hábil de fragmentos pertencentes a instantes diferentes. Tal é o modo habitual de representação do tempo na imagem pintada: ela retém, para cada uma das zonas significantes do espaço, um momento ("o momento mais favorável"), e opera depois por síntese, por colagem, por montagem. (AUMONT, 2004, p. 235)

A partir disso, podemos entender que cada imagem possui um sentido e ao serem colocadas em conjunto adquirem um sentido coletivo, em que a individualidade de cada imagem, a partir da relação com outras imagens, origina a história ou a narrativa que se pretende passar. O coletivo cria um novo conceito pelo sequenciamento das imagens fotográficas, como acontece no Big Picture.

A produção terceirizada e o processo coletivo jornalístico estão ligados à questão de autoria e de autenticidade. Antes os fotógrafos queriam ter seus nomes relacionados à produção, mas sites como o Big Picture (apesar de manterem os nomes dos fotógrafos), além de não produzirem material próprio, utilizam os materiais de terceiros sob outra ótica. Estamos num momento em que é possível colher imagens de diversas procedências e montar novos quadros, novas narrativas e painéis. Antigamente, havia mais necessidade de ter o domínio 
sobre a produção de imagens, fator este que está enfraquecido atualmente. A apropriação se tornou parte do processo jornalístico e tem total relação com 0 cenário cultural contemporâneo.

$\mathrm{O}$ ato de fotografar aliado a união de diversas fotografias sob um mesmo guarda-chuva editorial é determinante para a transmissão da mensagem visual do Big Picture. As etapas deste processo ressignificam o uso da imagem fotográfica. Trabalhamos no sentido do amadurecimento do olhar; daí a necessidade de promover novas reflexões sobre o impacto da fotografia na mídia online - um campo novo em pleno desenvolvimento com grandes possibilidades expressivas. O imediato, o instantâneo não precisam mais ser privilegiados, pois pode-se abrir uma porta à experimentação. Além disso, a compreensão fotográfica tem ampliados seus níveis de sensibilidade e de narrativização, fazendo com que todos os elementos da construção fotojornalística se tornem importantes. O meio, os recursos utilizados, o aspecto formal, a estética fotográfica e a observação formam, portanto, a base para a intenção primordial do fotojornalismo: contar histórias.

\section{Bibliografía}

AUMONT, Jacques. A imagem. Campinas: Editora Papirus, 2004.

BENJAMIN, Walter. A obra de arte na época de suas técnicas de reprodução. In: BENJAMIN, W. et al. Textos Escolhidos. São Paulo: Abril Cultural, 1975. (Coleção Os Pensadores).

BIG PICTURE. Disponível em <http://www.boston.com/bigpicture>. Acesso em 2011 e 2012.

BUITONI, Dulcília H. S. Imagens semoventes: fotografia e multimídia no webjornalismo. Animus: revista interamericana de comunicação midiática. Universidade Federal de Santa Maria, v. VI, oㅡ 1, p. 9-23, jan./jun. 2007.

BUITONI, Dulcília H. S. Hipermídia, hiperlinguagem e imagem complexa no webjornalismo. In: MARQUES, Ângela; COSTA, Caio Túlio, COSTA, Carlos; et al. Esfera Pública, Redes e Jornalismo. Rio de Janeiro: E-papers, 2009.

BUITONI, Dulcília H. S. Fotografia e Jornalismo: a informação pela imagem. São Paulo: Editora Saraiva, 2011.

BUITONI, Dulcília H. S. Imagens Contemporâneas: complexidades e interfaces. Revista Líbero. São Paulo, v. 15, n. 29, p. 71-80, jun. de 2012.

BUITONI, Dulcília H. S. Em busca de complexidades imagéticas. Trabalho apresentado no 
GP Fotografia do XII Encontro dos Grupos de Pesquisa em Comunicação, evento componente do XXXV Congresso Brasileiro de Ciências da Comunicação.

CATALÀ, Josep M. La imagen compleja. In: La Imagen Compleja. Barcelona: UAB, 2005.

CATALÀ, Josep M. A Forma do Real: introdução aos estudos visuais. São Paulo: Editora Summus, 2011.

HORN, Evelyse Lins. Fotografia-Expressão: a fotografia entre o documental e a arte contemporânea.

Disponível

em: <http://www.poscom.ufc.br/arquivos/fotografia_express\%E3o.pdf >. Acesso em novembro de 2012.

KOBRÉ, Kenneth. Fotojornalismo: uma abordagem profissional. Rio de Janeiro: Elsevier Editora LTDA, 2011.

ROUILLÉ, André. A Fotografia: entre documento e arte contemporânea. São Paulo: Editora Senac, 2009.

\section{Forma de citar este artículo en bibliografías}

PEREIRA DE CARVALHO, A. L. (2013): "O Fotojornalismo do Big Picture: notícias contadas por fotografias", en Revista PANGEA, 4, páginas 229 a 244. Red Académica Iberoamericana de Comunicación. Recuperado el _ de _ de 2_ de: http://www.revistapangea.org 